\title{
Evaluasi Kinerja Unit Instalasi Pengolahan Air Limbah Bojongsoang, Bandung
}

\author{
(Performance Evaluation of Wastewater Treatment Plant Unit Bojongsoang \\ Bandung)
}

\footnotetext{
Muhammad Ihsan Firdaus $^{1 *}$, Satyanto Krido Saptomo ${ }^{1}$, Joana Febrita ${ }^{1}$

${ }^{1}$ Departemen Teknik Sipil dan Lingkungan, Fakultas Teknologi Pertanian, Institut Pertanian Bogor. Jl. Raya Dramaga, Kampus IPB Dramaga, PO BOX 220, Bogor, Jawa Barat Indonesia

*Penulis korespondensi: ihsan326@gmail.com
}

Diterima: 28 Juli 2017

Disetujui: 15 Agustus 2017

\begin{abstract}
Wastewater treatment is required in order to improve waste water quality in accordance with the water quality standard and not harm the environment. The purpose of this research were to determine the quality of waste water based on BOD, COD, TSS, and $\mathrm{pH}$ parameters in the influent and effluent of each unit of wastewater treatment plant (IPAL), to compare the efficiency in reducing pollutant concentration with the literature, and comparing the quality of waste water at outlets with water quality standards. The research used samples taken in IPAL Bojongsoang Bandung and the test were done at PDAM Bandung laboratory. The highest efficiency of pollutant reduction in unit set A for TSS parameter was $66.67 \%$, $B O D 87.55 \%$, and COD $81.28 \%$. While for unit set $B$ the biggest pollutant reduction efficiency for TSS parameter was $55.88 \%, B O D 73.91 \%$, and COD $73.05 \%$. The processing unit set A had been eligible for $B O D$ and COD parameters for oxidation ditch (80-90\%). Concentrations at outlets in unit set A for TSS was $50 \mathrm{mg} / \mathrm{l}, B O D 27 \mathrm{mg} / \mathrm{l}, C O D 67 \mathrm{mg} / \mathrm{l}$, and $\mathrm{pH}$ 6.5, while in unit set B TSS was $75 \mathrm{mg} / \mathrm{l}$, BOD $21 \mathrm{mg} / \mathrm{l}$, COD $45 \mathrm{mg} / \mathrm{l}$, and $\mathrm{pH}$ 6.5. Comparing to the water quality standard the value of COD and $p H$ had fulfill the standard.
\end{abstract}

Key words: BOD, COD, performance evaluation, IPAL, pH, TSS

\section{PENDAHULUAN}

Daerah aliran sungai (DAS) Citarum merupakan DAS terbesar di Jawa Barat yang kini telah mengalami pencemaran yang sangat kuat akibat pemanfaatan yang melebihi daya dukungnya. Aktivitas yang ada di DAS ini antara lain adalah pertanian/perkebunan, pemukiman, industri, perikanan, dan pembangkit listrik (Garno 2002). Limbah domestik yang dihasilkan dari pemukiman di Kota Bandung yang termasuk kedalam daerah pelayanan PDAM Tirtawening Kota Bandung diolah di IPAL Bojongsoang Bandung. Komposisi limbah domestik umumnya didominasi oleh bahan organik, parameter yang umum digunakan berdasarkan PERMEN LHK
NOMOR P.68 Tahun 2016 tentang Baku Mutu Air Limbah Domestik diantaranya ternasuk biochemical oxygen demand (BOD), chemical oxygen demand (COD), total suspended solid (TSS), dan $\mathrm{pH}$.

Beban pencemaran domestik untuk setiap orang berbeda-beda. Setiap orang di Indonesia diperkirakan akan mengeluarkan BOD sebesar 25 g/orang/hari dan COD sebesar 57 g/orang/hari (Salim 2002). Rata-rata pemakaian air bersih setiap orang adalah 150 1/hari. Jumlah air limbah yang dihasilkan sebesar 105 1/org/hari (PDAM 2015). Air limbah memiliki pengaruh yang berbeda-beda terhadap kesehatan manusia, menurut Salim (2002) limbah cair domestik yang masuk ke badan air akam menyebabkan dampak terhadap 
kualitas air antara lain eutrophication, water borne disease, mempercepat korosivitas, dan biaya pengolahan bagi keperluan air bersih menjadi lebih mahal dan sulit akibat beban polutan yang tinggi dan beragam komposisinya.

Agar kualitas air limbah sesuai dengan baku mutu dan tidak membahayakan lingkungan, maka diperlukan desain instalasi pengolahan air limbah. Sarana air kotor secara perpipaan lengkap dengan instalasi pengolahan air limbah (IPAL) dibangun melalui proyek BUDP Dewi Sartika Tahap I dan Tahap II dalam rangka penataan sanitasi lingkungan di Kota Bandung dan dikelola oleh PDAM Kota Bandung. Instalasi pengolahan ini mempunyai kapasitas \pm $243.000 \mathrm{~m}^{3}$ dan dapat melayani \pm 400.000 jiwa penduduk untuk daerah pelayanan Bandung Timur, Bandung Tengah, dan Bandung Selatan. Instalasi ini dijalankan dengan proses melalui sistem kolam stabilisasi yang sangat bergantung kepada faktor alam. Instalasi ini terletak di Kecamatan Bojongsoang Kabupaten Bandung dengan areal $85 \mathrm{Ha}$ (PDAM 2015).

Hasil penelitian sebelumnya yang dilakukan Siregar (2004) di laboratorium Teknik Lingkungan Institut Teknologi Bandung menunjukkan bahwa pada tahun 2004 konsentrasi BOD di inlet bernilai $739,5 \mathrm{mg} / \mathrm{l}$ dan di outlet $53,39 \mathrm{mg} / \mathrm{l}$, sedangkan COD di inlet $134,5 \mathrm{mg} / \mathrm{l}$ dan di outlet 108,79 mg/l. Jika dibandingkan dengan baku mutu limbah cair SK.Gubernur Jabar No. 6 Tahun 1999 nilai BOD dan COD tidak masuk ke dalam standar yaitu $50 \mathrm{mg} / \mathrm{l}$ dan $100 \mathrm{mg} / \mathrm{l}$. Sehingga perlu dilakukan evaluasi kembali terhadap kinerja dari unit IPAL tersebut terlebih lagi karena ada pergantian nilai baku mutu air limbah domestik Peraturan Menteri Lingkungan Hidup dan Kehutanan Republik Indonesia 2016 Nomor 68 untuk nilai BOD 30 mg/l dan COD $100 \mathrm{mg} / \mathrm{l}$. Serta ditambahkan peninjauan dengan parameter TSS dan pH. Tujuan penelitian ini adalah mengetahui kualitas air limbah berdasarkan parameter BOD, COD, TSS, dan $\mathrm{pH}$ di influen serta efluen masingmasing unit, membandingkan kualitas air limbah di outlet dengan baku mutu, dan membandingkan efisiensi setiap unit pengolahan air limbah dalam menurunkan konsentrasi pencemar dengan literatur.

\section{METODOLOGI}

Pengumpulan data primer dilaksanakan selama bulan April 2017, sedangkan data primer diambil dari bulan Januari sampai Maret dari laboratorium BPAL Kota Bandung. Penelitian menggunakan sampel yang diambil di unit pengolahan air limbah Bojongsoang Bandung dan pengujian dilakukan di Laboratorium BPAL Kota Bandung. Alat yang digunakan pada penelitian ini adalah erlenmeyer, labu ukur, pipet, wingkler, oven, dan kertas saring. Bahan-bahan yang dibutuhkan adalah sampel air limbah, $\mathrm{KOH}, \mathrm{K}_{2} \mathrm{Cr}_{2} \mathrm{O}_{7} 0,1 \mathrm{~N}$, dan $\mathrm{H}_{2} \mathrm{SO}_{4}$. Pengambilan sampel dilakukan di inlet, outlet kolam anaerobik, outlet kolam fakultatif, dan outlet kolam maturasi dan dilakukan antara pukul 8-10 pagi. Pengambilan sampel dilakukan dengan dua metode yaitu metode grab dan time detention. Metode grab (langsung) merupakan metode pengambilan sampel dengan sekali pengambilan dari inlet sampai outlet langsung. Pengukuran metode time detention dilakukan dengan pengambilan sampel di inlet pada hari pertama dan selanjutnya di masing-masing kolam sesuai waktu detensinya. Metode pengambilan dengan metode time detention ini akan terpengaruh oleh kondisi cuaca karena cuaca dalam satu minggu tidak akan seragam dan akan mempengaruhi proses pengolahan pada kolam stabilisasi. 
Prosedur pengujian BOD dilakukan dengan metode manometri yaitu pegukuran oksigen terlarut yang dilakukan dengan penurunan tekanan udara akibat penurunan tekanan oksigen. Oksigen yang terlarut dalam air digunakan oleh mikroorganisme untuk mengurai zat organik. Pengurangan oksigen menyebabkan tekanan udara berkurang dan terbaca pada manometer air raksa. Langkah pertama, sampel limbah cair dimasukkan ke dalam botol BOD sebanyak $160 \mathrm{ml}$ kemudian ditutup. Pada tutupnya dimasukkan tiga butir $\mathrm{KOH}$ sebagai oksidator. Setelah itu botol sampel dimasukkan ke dalam alat BOD apparatus dan sampel disimpan selama 30 menit lalu botol disambungkan dengan alat pembaca digital. Konsentrasi BOD yang diambil adalah nilai BOD pada pengukuran hari kelima.

Prosedur pengujian TSS mengacu pada ketentuan yang berlaku (BSN 2004b). TSS (Total Suspended Solid) ditentukan dengan metode gravimetri. Sebanyak $100 \mathrm{ml}$ akuades disaring dengan kertas Whatman nomor 40. Kemudian kertas saring tersebut dipanaskan di dalam oven dengan suhu $105{ }^{\circ} \mathrm{C}$ selama 1 jam dan didinginkan dalam desikator selama 15 menit, lalu ditimbang berat awalnya. Diambil $100 \mathrm{ml}$ sampel limbah dengan menggunakan kertas saring yang telah diketahui beratnya, kemudian dikeringkan dalam oven dengan suhu $105{ }^{\circ} \mathrm{C}$ selama 1 jam. Selanjutnya didinginkan dalam desikator selama kurang lebih 15 menit, lalu ditimbang berat akhirnya. Kandungan total padatan tersuspensi dihitung dengan menggunakan persamaan (1) (BSN 2004b).

$\operatorname{TSS}\left(m g L^{-1}\right)=(b-a) x\left(\frac{1000}{100}\right)$

Keterangan :

a = berat awal kertas saring (mg)

$\mathrm{b} \quad=$ berat akhir kertas saring $(\mathrm{mg})$
Prosedur pengujian COD mengacu pada ketentuan yang berlaku (BSN 2004a) dengan refluks tertutup secara spektrofotometri. Penelitian dimulai dengan memasukkan sebanyak $2,5 \mathrm{ml}$ contoh uji air limbah ke dalam tabung COD, kemudian diambahkan 1,5 ml larutan $\mathrm{K}_{2} \mathrm{Cr}_{2} \mathrm{O}_{7}$ 0,1 $\mathrm{N}$ dan 3,5 ml larutan pereaksi $\mathrm{H}_{2} \mathrm{SO}_{4}$ pekat kemudian kedua larutan tersebut dihomogenkan. Tabung kemudian ditutup dengan klem lalu dipanaskan di COD reaktor selama 2 jam pada suhu $150^{\circ} \mathrm{C}$. Kemudian setelah di dinginkan, sampel dimasukkan ke dalam alat spektrofotometer dengan panjang gelombang $600 \mathrm{~nm}$ (BSN 2004a).

Prosedur pengujian $\mathrm{pH}$ mengacu pada ketentuan yang berlaku dengan menggunakan alat pH meter (BSN 2004c). Prosedur yang dilakukan adalah kalibrasi alat $\mathrm{pH}$-meter dengan larutan penyangga. Keringkan dengan kertas tisu selanjutnya bilas elektroda dengan air suling. Bilas elektroda dengan contoh uji. Celupkan elektroda ke dalam contoh uji sampai $\mathrm{pH}$ meter menunjukkan pembacaan yang tetap. Catat hasil pembacaan skala atau angka pada tampilan dari $\mathrm{pH}$ meter.

Perhitungan efisiensi dilakukan agar diketahui nilai efisiensi dari sistem pengolahan instalasi pengolahan air limbah (IPAL) dalam mengolah limbah domestik sebelum dialirkan ke badan air. Nilai efisiensi dihitung dengan persamaan (2).

$\%$ efisiensi $=\frac{A-B}{A} \times 100 \%$

Keterangan :

$\mathrm{A}=$ Kadar parameter pada inlet

$\mathrm{B}=$ Kadar parameter pada outlet

Kemudian hasil pengukuran dibandingkan dengan baku mutu yang digunakan untuk kualitas air limbah domestik yaitu Peraturan Menteri Lingkungan Hidup dan Kehutanan 
(PermenLHK 2016). Standar baku mutu tersebut dapat dilihat pada Tabel 1.

Tabel 1 Baku mutu air limbah domestik

\begin{tabular}{lcc}
\hline \multicolumn{1}{c}{ Parameter } & Satuan & Kadar maksimum \\
\hline $\mathrm{pH}$ & - & $6,0-9,0$ \\
$\mathrm{BOD}$ & $\mathrm{mg} / \mathrm{l}$ & 30 \\
$\mathrm{COD}$ & $\mathrm{mg} / \mathrm{l}$ & 100 \\
TSS & $\mathrm{mg} / \mathrm{l}$ & 30 \\
Minyak \& lemak & $\mathrm{mg} / \mathrm{l}$ & 5 \\
Amoniak & $\mathrm{mg} / \mathrm{l}$ & 10 \\
Total coliform & Jumlah/100ml & 3000 \\
Debit & 1/orang/hari & 100 \\
\hline
\end{tabular}

\section{HASIL DAN PEMBAHASAN}

Instalasi Pengolahan Air Limbah

Daerah pelayanan Instalasi Pengolahan Air Limbah Bojongsoang yaitu Kota Bandung sedangkan lokasi dari IPAL terletak di Kabupaten Bandung. IPAL Bojongsoang memiliki tujuan untuk mengolah limbah rumah tangga dan menurunkan tingkat pencemaran sungaisungai di Kota Bandung. Unit pengolahan yang terdapat di IPAL Bojongsoang ditampilkan pada Tabel 2. Tabel 3 menunjukkan perbandingan antara standar desain menurut beberapa literatur dengan kondisi desain di lapangan yang didapat. Meskipun desain sesuai namun apabila tidak disertai pemeliharaan dan pengoperasian yang baik maka hasil tidak akan maksimal. Kendala yang dapat terjadi pada unit mechanical bar screen yaitu ada sampah keras yang lolos dari bar screen awal dan dapat tersangkut pada rantai mechanical bar screen yang menyebabkan tidak berfungsinya alat. Hal tersebut dapat dikurangi apabila penyaringan pada bar screen awal sempurna atau tidak ada sampah yang lolos.

Tabel 2 Unit pengolahan di IPAL Bojongsoang

\begin{tabular}{lll}
\hline & Ideal & IPAL Bojongsoang \\
\hline Pre/Primary Treatment & Bar Screen & Ada \\
\cline { 2 - 3 } & Grit Removal unit & Ada \\
\cline { 2 - 3 } & Flotation unit & - \\
\cline { 2 - 3 } & Comminutor & - \\
\cline { 2 - 3 } & Fat Flotation & - \\
\cline { 2 - 3 } & Sedimentation & Ada \\
\hline Secondary Treatment & Tangki Aerasi & Tidak ada, digantikan \\
& Secondary & dengan 3 kolam: \\
& Sedimentation & anaerobik, fakultatif, \\
& Trickling Filter & maturasi \\
\hline Advance/Tertiary & Proses Kimia & - \\
\cline { 2 - 3 } Treatment & Proses Biologi & - \\
\cline { 2 - 3 } & Proses Fisika & - \\
\hline
\end{tabular}


Tabel 3 Perbandingan desain

\begin{tabular}{|c|c|c|c|}
\hline Parameter & Standar & Hasil & Keterangan \\
\hline \multicolumn{4}{|c|}{ Bar screen } \\
\hline Jarak antar kisi* & $2,5-5 \mathrm{~cm}$ & $5 \mathrm{~cm}$ & Sesuai \\
\hline \multicolumn{4}{|l|}{ Sump well } \\
\hline Kedalaman min.*** & $0,75 \mathrm{~m}$ & $1 \mathrm{~m}$ & Sesuai \\
\hline Luas min. $* * *$ & $0,25 \mathrm{~m}^{2}$ & $9 \mathrm{~m}^{2}$ & Sesuai \\
\hline \multicolumn{4}{|l|}{ Screw pump } \\
\hline Jumlah**** & 3 & 2 & $\begin{array}{l}\text { Satu unit tidak } \\
\text { berfungsi }\end{array}$ \\
\hline \multicolumn{4}{|c|}{ Mechanical bar screen } \\
\hline Jarak antar kisi* & $1,5-7,5 \mathrm{~cm}$ & $5 \mathrm{~cm}$ & Sesuai \\
\hline Conveyor belt $* * * *$ & - & - & Berfungsi \\
\hline \multicolumn{4}{|l|}{ Grit chamber } \\
\hline Waktu detensi* & $45-90 \mathrm{det}$ & - & Tidak ada data \\
\hline Periode pengurasan* & 41 hari & Situasional & Tidak sesuai \\
\hline Grit rake & Ada & Ada & Sesuai \\
\hline \multicolumn{4}{|c|}{ Kolam anaerobik } \\
\hline Luas area**** & $4,04 \mathrm{Ha}$ & $4,04 \mathrm{Ha}$ & Sesuai \\
\hline Kedalaman $* *$ & $2-6 m$ & $4 \mathrm{~m}$ & Sesuai \\
\hline Waktu detensi** & $<10$ hari & 2 hari & Sesuai \\
\hline Ketinggian lumpur** & $0,25-0,5 \mathrm{~m}$ & - & Tidak ada data \\
\hline \multicolumn{4}{|c|}{ Kolam fakultatif } \\
\hline Luas area**** & $29,8 \mathrm{Ha}$ & $28,29 \mathrm{Ha}$ & Tidak sesuai \\
\hline Kedalaman $* *$ & $1-2 \mathrm{~m}$ & $2 \mathrm{~m}$ & Sesuai \\
\hline Waktu detensi** & $5-30$ hari & $5-7$ hari & Sesuai \\
\hline \multicolumn{4}{|c|}{ Kolam maturasi/aerobic } \\
\hline Luas area**** & $32,5 \mathrm{Ha}$ & $32,33 \mathrm{Ha}$ & Tidak sesuai \\
\hline Kedalaman** & $0,3-0,6 \mathrm{~m}$ & $1,5 \mathrm{~m}$ & Tidak sesuai \\
\hline Waktu detensi** & $3-5$ hari & 3 hari & Sesuai \\
\hline Aerasi mekanis** & Ada & Tidak ada & Tidak sesuai \\
\hline
\end{tabular}

*: Metcalf and Eddy 2003; **: Grady et. al. 1999; ***: U.S. EPA 2001;

****: PDAM 2003

Waktu detensi pada unit grit chamber tidak didapatkan data. Waktu detensi yang tidak sesuai dengan standar desain akan menyebabkan unit grit chamber tidak bekerja dengan baik. Misal, pasir dapat terbawa oleh aliran dari unit karena tidak sempat mengendap. Ketinggian lumpur di kolam anaerobik juga tidak didapatkan data. Apabila ketinggian lumpur ini diatas standar yang ditentukan, hal tersebut dapat mengganggu proses yang terjadi pada kolam. Akibatnya, dapat mengurangi waktu detensi dan keadaan anaerobik pada kolam.

Masalah yang dapat mengganggu proses stabilisasi di kolam fakultatif salah satunya yaitu masuknya air dari jalan samping kolam dapat mengganggu proses stabilisasi. Kolam maturasi akan lebih baik jika diberikan alat aerasi untuk menghasilkan oksigen bagi bakteri aerob. Air keluaran dari kolam maturasi harus memenuhi standar baku air bersih namun belum dapat digunakan untuk konsumsi. Setelah melalui seluruh proses 
pengolahan, air dialirkan menuju sungai Citarum.

Akan lebih baik jika diberikan

a. ilustrasi berupa foto atau gambar IPAL secara keseluruhan

b. Diagram alir proses pengolahan limbah dari inlet sampai outlet, termasuk produk samping dari masing-masing unit diolahnya seperti apa atau diumpankan ke mana

\section{Kualitas Air Limbah}

Pemeriksaan BOD diperlukan

untuk menentukan beban pencemaran akibat air buangan dan untuk mendesain sistem pengolahan secara biologis (Alaerts dan Santika 1987). Hasil pengukuran kadar BOD di inlet dan outlet untuk dua set unit yaitu set A dan set B untuk metode grab disajikan pada Gambar 1. Berdasarkan Gambar 1, untuk unit kompartemen set A nilai untuk pengukuran BOD pada bulan Februari menunjukkan nilai terbesar pada inlet yaitu $233 \mathrm{mg} / \mathrm{l}$ dan untuk inlet set B memiliki nilai terbesar pada bulan April dengan $184 \mathrm{mg} / \mathrm{l}$. Nilai di inlet tersebut jika mengacu pada karakteristik limbah cair (Metcalf and Eddy 2003) dengan kadar BOD rata-rata $220 \mathrm{mg} / \mathrm{l}$ maka konsentrasi di inlet untuk set A pada bulan Februari ini melebihi dari kadar rata-rata dari karakteristik limbah cair. Selebihnya kadar di inlet pada bulan lainnya masuk ke dalam kriteria.

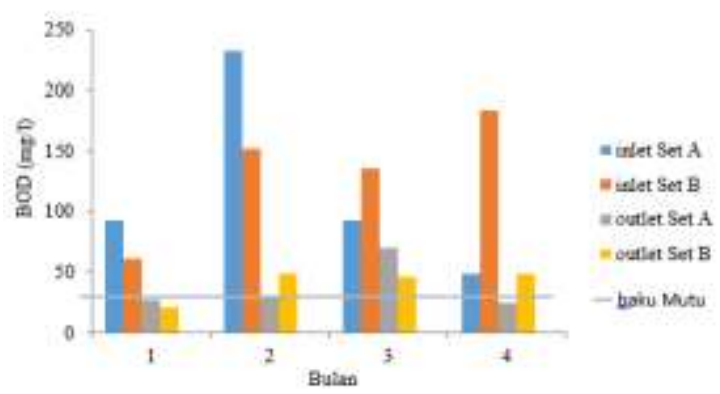

Gambar 1 Kadar BOD dengan metode grab
Konsentrasi di outlet terkecil untuk set A berada pada bulan Januari yaitu 27 $\mathrm{mg} / \mathrm{l}$ dan konsentrasi terbesar di outlet set A yaitu $70 \mathrm{mg} / \mathrm{l}$. Sementara untuk outlet set B memiliki nilai terkecil pada bulan Januari dengan $21 \mathrm{mg} / \mathrm{l}$ dan terbesar pada bulan Februari dengan 49 mg/l. Kompartemen set A untuk bulan Januari, Februari, dan April sudah memenuhi kriteria baku mutu yaitu $30 \mathrm{mg} / \mathrm{l}$ (KemenLHK 2016), sedangkan untuk set B hanya pada bulan Januari saja yang memenuhi baku mutu. Hasil pengukuran metode time detention disajikan pada Gambar 2. Berdasarkan Gambar 2 nilai di inlet tersebut masuk dengan kadar BOD rata-rata $220 \mathrm{mg} / \mathrm{l}$ (Metcalf and Eddy 2003) karena nilai terbesar yaitu $152 \mathrm{mg} / \mathrm{l}$ pada bulan Februari. Sementara untuk kadar BOD di outlet untuk set A maupun set B tidak ada yang memenuhi baku mutu (KemenLHK 2016). Nilai terkecil untuk set A di outlet yaitu $42 \mathrm{mg} / \mathrm{l}$ dan di set B $56 \mathrm{mg} / \mathrm{l}$.

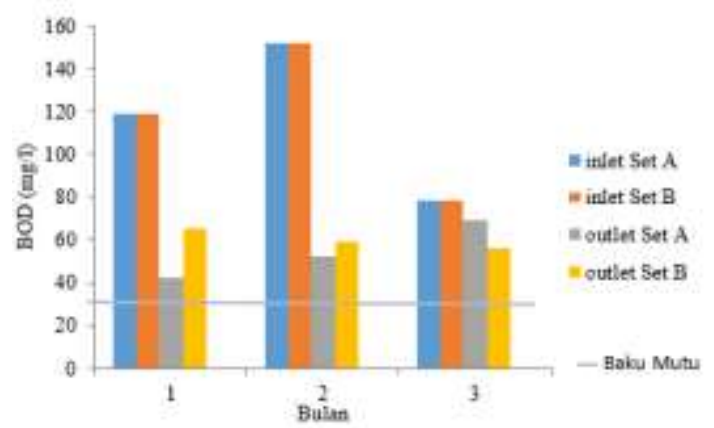

Gambar 2 Kadar BOD dengan metode time detention

Tabel 4 menunjukkan nilai efisiensi pengurangan konsentrasi BOD. Untuk set A pada bulan Februari menunjukkan nilai terbesar dengan efisiensi pengurangan $87,55 \%$, demikian juga untuk set $B$ nilai efisiensi terbesar adalah 67,76\%. Efisiensi untuk pengolahan set A masuk ke dalam rentang kriteria menurut Qasim (1999) dengan rentang $80-90 \%$ untuk unit oxidation ditch, sementara itu untuk pengolahan di set $\mathrm{B}$ belum memenuhi kriteria tersebut. 
Nilai efisiensi terkecil untuk set A yaitu $11,54 \%$ dan set B 28,21\% dengan metode time detention. Meskipun nilai efisiensi tidak masuk ke dalam rentang kriteria

Tabel 4 Efisiensi (\%) pengurangan konsentrasi BOD

\begin{tabular}{llcllc}
\hline \multirow{2}{*}{ Bulan } & \multicolumn{3}{c}{ Metode grab } & & \multicolumn{2}{c}{ Metode time detention } \\
\cline { 2 - 3 } \cline { 5 - 6 } & Set A & Set B & & Set A & Set B \\
\hline Januari & 70,97 & 65,57 & & 64,71 & 45,38 \\
Februari & 87,55 & 67,76 & & 65,79 & 61,18 \\
Maret & 24,73 & 66,18 & & 11,54 & 28,21 \\
April & 48,98 & 73,91 & - & - \\
\hline
\end{tabular}

Pengukuran COD (chemical oxygen demand) merupakan uji yang menentukan jumlah oksigen yang dibutuhkan oleh bahan oksidan untuk mengoksidasi bahan-bahan organik yang terdapat di dalam air. Hasil pengukuran COD untuk metode grab ditampilkan pada Gambar 3. Konsentrasi di outlet terkecil untuk set A berada pada bulan April yaitu 63,95 mg/l dan konsentrasi terbesar di outlet set A yaitu $99 \mathrm{mg} / \mathrm{l}$. Sementara untuk outlet set B memiliki nilai terkecil pada bulan Januari dengan $45 \mathrm{mg} / \mathrm{l}$ dan terbesar pada bulan Februari dengan $102 \mathrm{mg} / \mathrm{l}$. Konsentrasi COD di outlet sudah memenuhi kriteria baku mutu (KemenLHK 2016) yaitu 100 mg/l. Tetapi pada bulan Februari di set B nilai di outlet melebihi baku mutu dengan $102 \mathrm{mg} / \mathrm{l}$ akan tetapi nilai tersebut hanya melebihi sedikit saja dari baku mutu. Jelaskan, mengapa nilainya bisa bervariasi seperti itu.

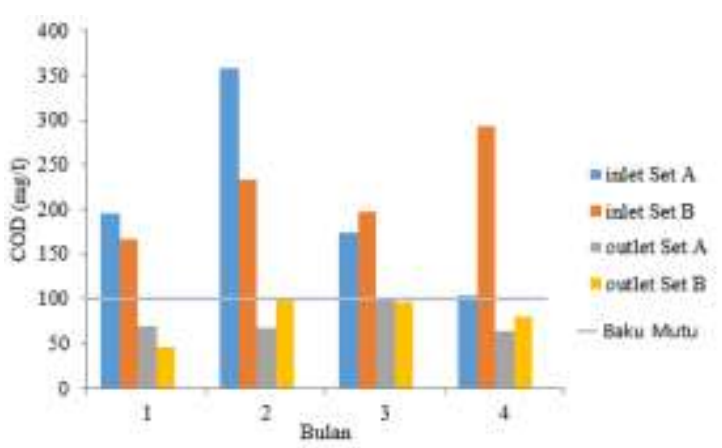

Gambar 3 Kadar COD dengan metode grab namun hasil di outlet dapat memenuhi baku mutu karena hal tergantung pada konsentrasi di inlet dan cuaca di lokasi. 
90\% untuk unit oxidation ditch sementara untuk pengolahan di set $B$ belum. Sementara nilai efisiensi terkecil untuk set
A yaitu $18,85 \%$ dan set B $18,85 \%$ dengan metode time detention.

Tabel 5 Efisiensi (\%) pengurangan konsentrasi COD

\begin{tabular}{llllll}
\hline \multirow{2}{*}{ Bulan } & \multicolumn{2}{l}{ Metode grab } & & \multicolumn{2}{c}{ Metode time detention } \\
\cline { 2 - 3 } \cline { 6 - 6 } & Set A & Set B & & Set A & Set B \\
\hline Januari & 64,10 & 73,05 & & 53,76 & 46,24 \\
Februari & 81,28 & 56,41 & 61,54 & 60,26 \\
Maret & 42,77 & 51,52 & & 18,85 & 18,85 \\
April & 37,87 & 72,98 & - & - \\
\hline
\end{tabular}

Kandungan zat-zat organik dalam limbah yang tinggi akan menyebabkan lebih banyak oksigen yang dibutuhkan untuk mendegradasi zat-zat organik tersebut, sehingga nilai BOD dan COD limbah akan tinggi. Oleh karena itu untuk menurunkan nilai BOD dan COD limbah, perlu dilakukan pengurangan zat-zat organik yang terkandung di dalam limbah sebelum dibuang ke perairan. Pengurangan kadar zat-zat organik yang ada pada limbah cair sebelum dibuang ke perairan, dapat dilakukan dengan mengadsorpsi zat-zat tersebut menggunakan adsorben. Salah satu adsorben yang memiliki kemampuan adsorpsi yang besar adalah zeolit alam (Wahistina et al. 2013).

$$
\text { Selanjutnya dilakukan }
$$
pemeriksaan terhadap parameter TSS. Penentuan zat padat tersuspensi (TSS) berguna untuk mengetahui kekuatan pencemaran air limbah domestik, dan juga berguna untuk penentuan efisiensi unit pengolahan air (BAPPEDA 1995). Hasil pengukuran TSS untuk metode grab ditampilkan pada Gambar 5.

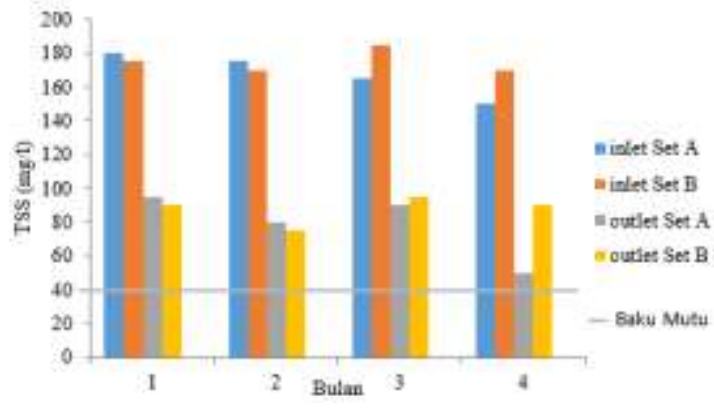

Gambar 5 Kadar TSS dengan metode grab

Berdasarkan Gambar 5 untuk unit kompartemen set A nilai untuk pengukuran TSS pada bulan Januari menunjukkan nilai terbesar pada inlet yaitu $180 \mathrm{mg} / \mathrm{l}$ dan untuk inlet set B memiliki nilai terbesar pada bulan Maret dengan $185 \mathrm{mg} / \mathrm{l}$. Nilai di inlet tersebut jika mengacu pada karakteristik limbah cair (Metcalf and Eddy 2003) dengan kadar TSS rata-rata $220 \mathrm{mg} / \mathrm{l}$ maka konsentrasi di inlet untuk set A dan set B telah masuk ke dalam kriteria.

Konsentrasi di outlet terkecil untuk set A berada pada bulan April yaitu 50 $\mathrm{mg} / \mathrm{l}$ dan konsentrasi terbesar di outlet set A yaitu $90 \mathrm{mg} / \mathrm{l}$. Sementara untuk outlet set B memiliki nilai terkecil pada bulan Februari dengan $75 \mathrm{mg} / \mathrm{l}$ dan terbesar pada bulan dengan $90 \mathrm{mg} / \mathrm{l}$. Konsentrasi TSS di outlet belum memenuhi kriteria baku mutu yaitu $30 \mathrm{mg} / \mathrm{l}$ (KemenLHK 2016). Hasil pengukuran metode time detention disajikan pada Gambar 6. 


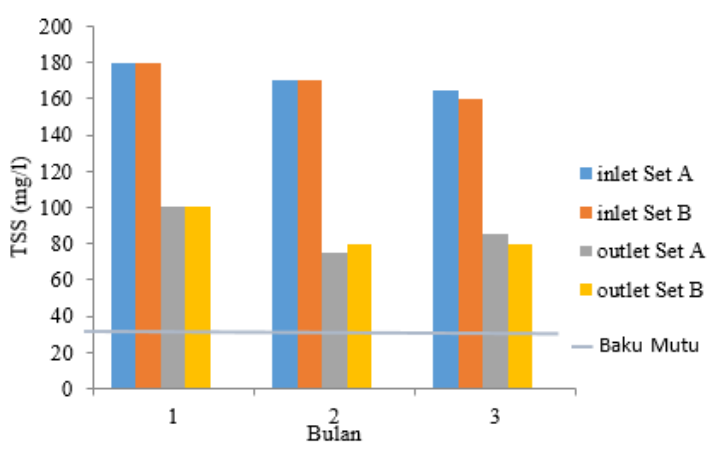

Gambar 6 Kadar TSS dengan metode time detention

Berdasarkan Gambar 6 nilai di inlet tersebut masuk dengan kadar TSS rata-rata $220 \mathrm{mg} / \mathrm{l}$ (Metcalf and Eddy 2003) karena nilai terbesar yaitu $180 \mathrm{mg} / \mathrm{l}$ pada bulan Januari. Kadar TSS di outlet untuk set A maupun set B juga belum memenuhi baku mutu yaitu $30 \mathrm{mg} / \mathrm{l}$ (KemenLHK 2016). Nilai terkecil untuk set A di outlet yaitu $75 \mathrm{mg} / \mathrm{l}$ dan di set B $80 \mathrm{mg} / \mathrm{l}$. Efisiensi pengurangan konsentrasi TSS dapat dilihat pada Tabel 6.

Tabel 6 Efisiensi (\%) pengurangan konsentrasi TSS

\begin{tabular}{|c|c|c|c|c|}
\hline \multirow{2}{*}{ Bulan } & \multicolumn{2}{|c|}{ Metode grab } & \multicolumn{2}{|c|}{$\begin{array}{l}\text { Metode } \\
\text { detention }\end{array}$} \\
\hline & Set A & Set B & Set A & Set B \\
\hline Januari & 47,22 & 48,57 & 44,44 & 44,44 \\
\hline Februari & 54,29 & 55,88 & 55,88 & 52,94 \\
\hline Maret & 45,45 & 48,65 & 48,48 & 50,00 \\
\hline April & 66,67 & 47,06 & - & - \\
\hline
\end{tabular}

Tabel 6 menunjukkan nilai efisiensi pengurangan konsentrasi TSS, untuk set A pada bulan April menunjukkan nilai terbesar dengan efisiensi pengurangan 66,67\%. Pada pengukuran TSS untuk set B nilai efisiensi terbesar adalah $55,88 \%$ pada bulan Februari. Efisiensi untuk pengolahan set A maupun $\mathrm{B}$ belum masuk ke dalam rentang kriteria menurut Qasim (1999) dengan rentang $80-90 \%$ untuk unit oxidation ditch. Sementara nilai efisiensi terkecil untuk set A yaitu $44,44 \%$ dan set B $44,44 \%$ dengan metode time detention. Konsentrasi di outlet yang terkandung dalam air limbah bergantung pada konsentrasi di inlet dan cuaca di lapangan. Masuknya padatan tersuspensi (TSS) ke dalam air dapat menimbulkan kekeruhan air, yang menyebabkan menurunnya laju fotosintesis fitoplankton dan tumbuhan air lainnya, sehingga produktivitas primer perairan menurun (Fardiaz 1992).

Pengurangan kadar TSS dapat dilakukan salah satunya dengan menggunakan koagulasi dan flokulasi. Koagulasi merupakan proses terjadinya peristiwa pembentukan partikel-partikel kecil dengan menggunakan bahan koagulan (PAC atau alum) dan flokulasi merupakan proses pengadukan lambat terhadap partikel yang terdestabilisasi dan membentuk pengendapan flok dengan cepat (Gurses 2003). Pengurangan TSS juga dapat dilakukan dengan penggunaan jaring sebagai alat penyaring yang diletakkan pada setiap inlet, akan tetapi perlu dilakukan maintenance yang rutin agar padatan pada saringan tidak menyumbat. Selanjutnya untuk parameter $\mathrm{pH}$, penentuan $\mathrm{pH}$ sangat berpengaruh terhadap korosi yang biasanya terjadi pada pipa distribusi air (Effendi dan Hefni 2003). Hasil pengukuran $\mathrm{pH}$ disajikan pada Gambar 7.

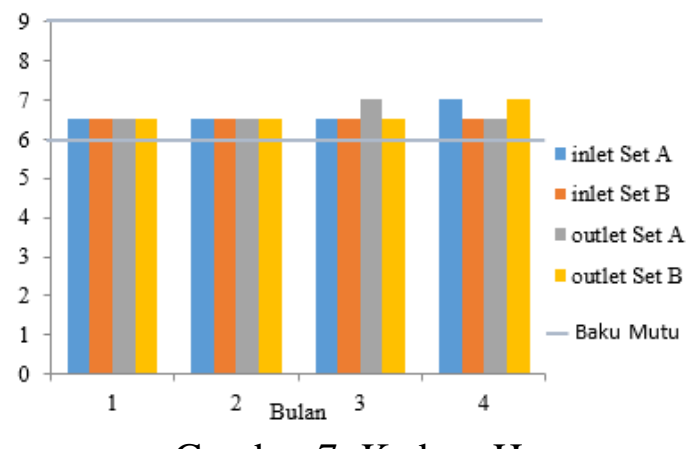

Gambar 7 Kadar pH 
Berdasarkan Gambar 7 untuk unit kompartemen set $\mathrm{A}$ dan set $\mathrm{B}$ nilai pengukuran $\mathrm{pH}$ di inlet yaitu dalam rentang 6,5 sampai 7. Hasil di outlet juga menunjukkan nilai yang tidak jauh berbeda dengan di inlet yaitu rentang 6,5 sampai 7. Jika mengacu pada baku mutu yang berlaku (KemenLHK 2016) parameter $\mathrm{pH}$ telah masuk ke dalam rentang kadar yang dibolehkan yaitu 6 sampai 9.

Salah satu penyebab konsentrasi parameter yang berada di atas baku mutu yang ditetapkan (KemenLHK 2016) adalah adanya pergantian standar baku mutu dari SK.Gubernur Jabar No. 6 Tahun 1999 tentang Baku Mutu Limbah Cair Bagi Kegiatan Industri di Jawa Barat yang memiliki nilai konsentrasi parameter yang berbeda. Pada perencanaan awal desain IPAL, baku mutu yang menjadi acuan adalah baku mutu lama sehingga adanya pergantian menyebabkan konsentrasi yang awalnya sudah memenuhi baku mutu dengan desain awal IPAL menjadi tidak masuk baku mutu khususnya untuk parameter TSS yang memiliki perbedaan baku mutu sangat jauh. Nilai konsentrasi baku mutu SK.Gubernur Jabar No. 6 Tahun 1999 untuk parameter BOD, COD, TSS, dan pH disajikan pada Tabel 7.

Tabel 7 Baku mutu limbah cair SK.Gubernur Jabar No. 6 Tahun 1999

\begin{tabular}{ccc}
\hline Parameter & Satuan & Konsentrasi (mg/l) \\
\hline BOD & $\mathrm{mg} / \mathrm{l}$ & 50 \\
COD & $\mathrm{mgl} / \mathrm{l}$ & 100 \\
TSS & $\mathrm{mg} / \mathrm{l}$ & 200 \\
$\mathrm{pH}$ & - & $6,0-9,0$ \\
\hline
\end{tabular}

Satu set IPAL memiliki tiga kolam anaerobik yang berasal dari satu inlet kemudian dibagi lagi ke dalam dua kolam fakultatif, menuju ke kolam maturasi 1 dan berakhir di kolam maturasi 2 sebagai outlet. Konsentrasi pencemar diukur pada masing-masing unit pengolahan dimulai dari inlet, kolam anaerobik (An), kolam fakultatif $(\mathrm{F})$, dan kolam maturasi (M) yang disajikan pada Tabel 8.

Tabel 8 Hasil pengukuran parameter Bulan April

\begin{tabular}{|c|c|c|c|c|c|}
\hline Tanggal & Lokasi Sampling & $\begin{array}{l}\mathrm{TSS} \\
(\mathrm{mg} / \mathrm{l})\end{array}$ & $\begin{array}{l}\text { BOD } \\
(\mathrm{mg} / \mathrm{l})\end{array}$ & $\begin{array}{l}\text { COD } \\
(\mathrm{mg} / \mathrm{l})\end{array}$ & $\mathrm{pH}$ \\
\hline \multirow[t]{9}{*}{$4 / 4 / 17$} & \multicolumn{5}{|l|}{ IPAL BJS set A } \\
\hline & 1 INLET & 150 & 49 & 102,93 & 7 \\
\hline & $2 \quad$ AN1A & 70 & 55 & 104,75 & 6,5 \\
\hline & AN2A & 80 & 31 & 104,55 & 6,5 \\
\hline & $4 \quad \mathrm{AN} 3 \mathrm{~A}$ & 70 & 76 & 159,66 & 7 \\
\hline & F1A & 50 & 58 & 108,97 & 7 \\
\hline & $\mathrm{F} 2 \mathrm{~A}$ & 60 & 65 & 136,52 & 7 \\
\hline & M1A & 60 & 50 & 105,78 & 7 \\
\hline & $8 \quad \mathrm{M} 2 \mathrm{~A}$ & 50 & 25 & 63,95 & 6,5 \\
\hline \multirow[t]{8}{*}{$6 / 4 / 17$} & \multicolumn{5}{|l|}{ IPAL BJS set B } \\
\hline & 1 INLET & 170 & 184 & 293,65 & 6,5 \\
\hline & 2 AN1B & 80 & 41 & 134,19 & 6 \\
\hline & 3 AN2B & 70 & 59 & 149,95 & 6,5 \\
\hline & 4 AN3B & 70 & 42 & 123,07 & 6 \\
\hline & $5 \quad$ F1B & 40 & 58 & 108,93 & 6 \\
\hline & $6 \quad \mathrm{~F} 2 \mathrm{~B}$ & 60 & 47 & 105,86 & 6,5 \\
\hline & 7 M1B & 60 & 34 & 83,77 & 6,5 \\
\hline
\end{tabular}




\begin{tabular}{llllll}
\hline Tanggal & Lokasi Sampling & $\begin{array}{l}\text { TSS } \\
(\mathrm{mg} / \mathrm{l})\end{array}$ & $\begin{array}{l}\text { BOD } \\
(\mathrm{mg} / \mathrm{l})\end{array}$ & $\begin{array}{l}\text { COD } \\
(\mathrm{mg} / \mathrm{l})\end{array}$ & $\mathrm{pH}$ \\
\hline 8 & M2B & 90 & 48 & 79,34 & 7 \\
\hline
\end{tabular}

Berdasarkan Tabel 8, untuk set B adalah TSS $100 \mathrm{mg} / \mathrm{l}$, BOD $65 \mathrm{mg} / \mathrm{l}$, parameter BOD dan COD pada set A di COD $102 \mathrm{mg} / \mathrm{l}$, dan $\mathrm{pH} 7$.

kolam anaerobik 1 mengalami kenaikan konsentrasi dari inlet BOD $49 \mathrm{mg} / \mathrm{l}$ dan COD 102,93 mg/l menjadi BOD $55 \mathrm{mg} / \mathrm{l}$ dan COD 104,75 mg/l. Begitu pula dengan kolam anaerobik 3 yang mengalami kenaikan hingga BOD $76 \mathrm{mg} / 1$ dan COD 159,66 mg/l. Hal ini menunjukkan adanya masalah yang terjadi di kolam anaerobik 1 dan 3 set A sehingga terjadi pendangkalan kolam akibat sedimentasi. Salah satu upaya pengurangan sedimentasi yang berlebih ini dapat dilakukan dengan cara pengerukan secara berkala.

Kemudian, untuk kolam pada set B ditemukan nilai konsentrasi parameter yang naik pada kolam maturasi 2 yang berasal dari kolam maturasi 1 . Nilai untuk parameter TSS dan BOD pada kolam maturasi 1 yaitu TSS $60 \mathrm{mg} / \mathrm{l}$ dan BOD 34 $\mathrm{mg} / \mathrm{l}$ sedangkan pada kolam maturasi 2 mengalami kenaikan konsentrasi dan didapatkan hasil TSS $90 \mathrm{mg} / \mathrm{l}$ dan BOD $48 \mathrm{mg} / \mathrm{l}$, sehingga ada kemungkinan terjadi masalah pada kolam maturasi 2 . Berdasarkan pengamatan di lapangan pada kolam maturasi 2 ini dijadikan warga sebagai kolam ternak ikan yang diperkirakan mempengaruhi kualitas air di kolam tersebut.

\section{KESIMPULAN}

Konsentrasi parameter terkecil di outlet unit set A untuk TSS adalah 50 $\mathrm{mg} / \mathrm{l}$, BOD $27 \mathrm{mg} / \mathrm{l}$, COD $67 \mathrm{mg} / \mathrm{l}$, dan pH 6,5. Konsentrasi parameter terkecil di outlet unit set B adalah TSS $75 \mathrm{mg} / \mathrm{l}$, BOD $21 \mathrm{mg} / \mathrm{l}$, COD $45 \mathrm{mg} / \mathrm{l}$, dan $\mathrm{pH}$ 6,5. Konsentrasi parameter terbesar di outlet unit set A untuk TSS adalah $100 \mathrm{mg} / \mathrm{l}$, BOD $70 \mathrm{mg} / \mathrm{l}$, COD $99 \mathrm{mg} / \mathrm{l}$, dan $\mathrm{pH} 7$. Konsentrasi parameter terbesar untuk unit NOMOR P.68 Tahun 2016 tentang Baku Mutu Air Limbah Domestik, baku mutuuntuk TSS, BOD, COD dan $\mathrm{pH}$ berturut-turut sebesar $30 \mathrm{mg} / \mathrm{l}, \quad 30$ $\mathrm{mg} / \mathrm{l}, 100 \mathrm{mg} / \mathrm{l}$, dan 6-. Untuk parameter COD dan $\mathrm{pH}$ sudah memenuhi kriteria yang ditetapkan oleh baku mutu. Beberapa parameter BOD sudah masuk ke dalam baku mutu, tetapi lebih banyak hasil yang tidak memenuhi baku mutu.

Efisiensi pengurangan pencemar terbesar pada unit set A untuk parameter TSS yaitu $66,67 \%$, BOD yaitu $87,55 \%$, dan COD yaitu $81,28 \%$. Sementara untuk unit pada set $\mathrm{B}$ efisiensi pengurangan pencemar terbesar pada unit set B untuk parameter TSS yaitu 55,88\%, BOD yaitu $73,91 \%$, dan COD yaitu $73,05 \%$. Jika mengacu pada kriteria tingkatan pencapaian pengolahan dari unit operasi dan unit proses untuk oxidation ditch adalah $80-90 \%$ unit pengolahan di set $\mathrm{A}$ telah memenuhi syarat untuk parameter BOD dan COD.

\section{DAFTAR PUSTAKA}

Alaerts G, Santika SS. 1984. Metoda Penelitian Air. Surabaya (ID): Usaha Nasional.

[BAPPEDA] Badan Perencanaan Pembangunan Daerah TK. I Jawa Timur. 1995. Panduan Pelatihan Manajemen Laboratorium. Surabaya (ID): BAPPEDA.

[BSN] Badan Standardisasi Nasional. 2004a. Air dan air limbah Bagian 2: Cara Uji Kebutuhan Oksigen Kimiawi (KOK) dengan Refluks Tertutup Secara 
Spektrofotometri. SNI 06-6989.22004. Jakarta (ID): BSN.

[BSN] Badan Standardisasi Nasional. 2004b. Air dan air limbah Bagian 3: Cara Uji Padatan Tersuspensi Total (Total Suspended Solid, TSS) Secara Gravimetri. SNI 06-6989.3-2004. Jakarta (ID): BSN.

[BSN] Badan Standardisasi Nasional. 2004c. Air dan air limbah Bagian 11: Cara uji derajat keasaman $\quad(\mathrm{pH}) \quad$ dengan menggunakan alat $\mathrm{pH}$ meter. SNI 06-6989.11-2004. Jakarta (ID): BSN.

Effendi, Hefni. 2003. Telaah Kualitas Air. Yogyakarta (ID): Kanisius.

Fardiaz S. 1992. Polusi Air \& Udara. Yogyakarta (ID): Kanisius.

Garno YS. 2002. Beban Pencemaran Limbah Perikanan Budidaya dan Yutrofikasi di Perairan Waduk pada DAS Citarum. Jurnal Teknologi Lingkungan. 3(2): 112120.

Grady CP, Lim HC, Daigger GT. 1999. Biological Wastewater Treatment, Second Edition. New York (US): Marcel Dekker Inc.

Gurses A. 2003. Removal of Remazol Red $\mathrm{RB}$ by Using $\mathrm{Al}(\mathrm{III})$ as Coagulant Flocculant: Effect of Some Variables on Settling Velocity. Turkey: Ataturk University. Journal of Water, Air, and Soil Pollution. 146(1): 297-318.

[KemenLHK] Kementerian Lingkungan Hidup dan Kehutanan Republik Indonesia. 2016. Baku Mutu Air Limbah Domestik. Peraturan Menteri Lingkungan Hidup dan Kehutanan Republik Indonesia Nomor

P.68/Menlhk/Setjen/Kum.1/8/2016
- Jakarta (ID): Kementerian Lingkungan Hidup dan Kehutanan Republik Indonesia.

MetCalf and Eddy. 2003. Wastewater Engineering Treatment, Disposal, Reuse, $4^{\text {th }}$ edition. New York (US): McGraw-Hill Series Water Resource and Enviromental Engineering.

Nasution A. 2003. Limbah Perkotaan. Jakarta (ID): Gramedia.

[PDAM] Perusahaan Daerah Air Minum. 2015. Air Limbah. Bandung (ID): PDAM Tirtawening Kota Bandung. (pambdg.co.id)

[Pemprov Jabar] Pemerintah Provinsi Jawa Barat. 1999. Baku mutu limbah cair bagi kegiatan industri di Jawa Barat. Surat Keputusan Gubernur Jabar No. 6 Tahun 1999. Bandung(ID): Pemprov Jabar.

Qasim SR. 1999. Wastewater Treatment Plants-Planning, Design, and Operation, Second Ed. New York (US): CRC Press.

Salim H. 2002. Beban Pencemaran Limbah Domestik dan Pertanian di DAS Citarum Hulu. Jurnal Teknologi Lingkungan. 3(2): 107111.

Siregar S. 2004. Studi Sistim Operasi dan Pemeliharaan (O\&P) Instalasi Pengolahan Air Limbah (IPAL) (Studi Kasus IPAL Bojongsoang Kota Bandung). [Tesis]. Semarang (ID): Universitas Diponegoro.

[U.S. EPA] U.S. Environmental Protection Agency. 2011. Principles of Design and Operations of Wastewater Treatment Pond Systems for Plant Operators, Engineers, and Managers. Ohio (US): U.S. EPA.

Wahistina R, Ellyke, Pujiati RS. 2013. Analisis Perbedaan Penurunan 
Kadar BOD Dan COD pada

Limbah Cair Industri Tahu

Menggunakan Zeolit (Studi di

Pabrik Tahu di Desa Kraton

Kecamatan Kencong Kabupaten

Jember). [Artikel Ilmiah]. Jember

(ID): Universitas Jember. 
JSIL ～M. Ihsan Firdaus dkk: Evaluasi Kinerja Unit IPAL Bojongsaang Bandung 